\title{
New environment for a two-dimensional topological insulator with hexagonal channels hosting diiodido-bismuthate $(\mathrm{I})$ anions in singlet state
}

\section{Supporting Information}

\author{
Bertold Rasche ${ }^{1}$, Wouter Van den Broek ${ }^{3}$ and Michael Ruck ${ }^{1,2^{*}}$ \\ 1 Department of Chemistry and Food Chemistry, TU Dresden, 01062 Dresden, Germany \\ 2 Max Planck Institute for Chemical Physics of Solids, 01187 Dresden, Germany \\ 3 Institute of Experimental Physics, University of Ulm, 89069 Ulm, Germany
}

Table S1: Extrapolated principal mean square displacements $\left(/ \mathrm{ro}^{-1} \mathrm{pm}^{2}\right)$ at $\mathrm{o} \mathrm{K}$ together with the mean value and the standard deviation for all atoms in $\mathrm{Bi}_{3} \mathrm{Pt}_{9} \mathrm{I}_{14}$. Bi 4 , $\mathrm{I}_{1}, \mathrm{I}_{2}$ and $\mathrm{I}_{5}$ are residing in the hexagonal the channels.

\begin{tabular}{cccccc}
\hline atom & \multicolumn{2}{c}{$\begin{array}{c}\text { principal mean square } \\
\text { displacement at oK }\end{array}$} & $\begin{array}{c}\text { mean } \\
\text { value }\end{array}$ & $\begin{array}{c}\text { standard } \\
\text { deviation }\end{array}$ \\
\hline Pt1 & 2.7 & 1.9 & 2.2 & 2.3 & 0.4 \\
Pt2 & 2.2 & 2.1 & 2.4 & 2.3 & 0.1 \\
Bi1 & 2.9 & 2.5 & 2.2 & 2.5 & 0.3 \\
Bi2 & 4.2 & 2.5 & 2.7 & 3.1 & 0.9 \\
Bi3 & 3.5 & 2.3 & 1.9 & 2.6 & 0.9 \\
Bi4 & 4.9 & 3.5 & 3.5 & 4.0 & 0.8 \\
I1 & 4.0 & 5.0 & 5.0 & 4.7 & 0.6 \\
I2 & 6.5 & 2.2 & 2.2 & 3.6 & 2.5 \\
I3 & 6.7 & 4.5 & 2.6 & 4.6 & 2.0 \\
I4 & 5.5 & 4.4 & 3.4 & 4.4 & 1.1 \\
I5 & 7.1 & 7.1 & 6.4 & 6.8 & 0.4 \\
\hline
\end{tabular}




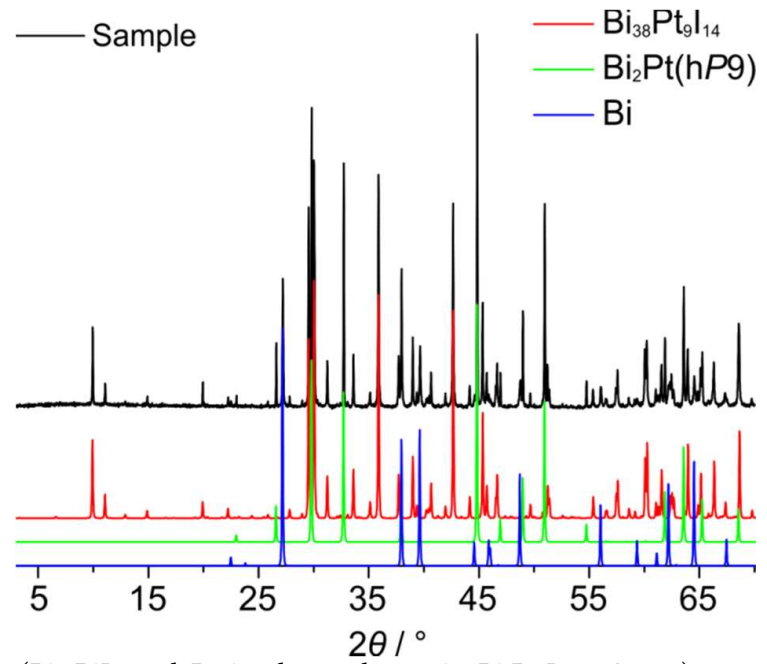

Figure S1: PXRD data of a sample $\left(\mathrm{Bi}, \mathrm{BiI}_{3}\right.$ and $\mathrm{Pt}$ in the molar ratio Bi:Pt:I = 38:9:14) annealed for one week at $290{ }^{\circ} \mathrm{C}$; and reference PXRD-patterns of $\mathrm{Bi}_{38} \mathrm{Pt}_{9} \mathrm{I}_{14}$, $\mathrm{Bi}$ and $\mathrm{Bi}_{2} \mathrm{Pt}\left(h P_{9}\right)$.

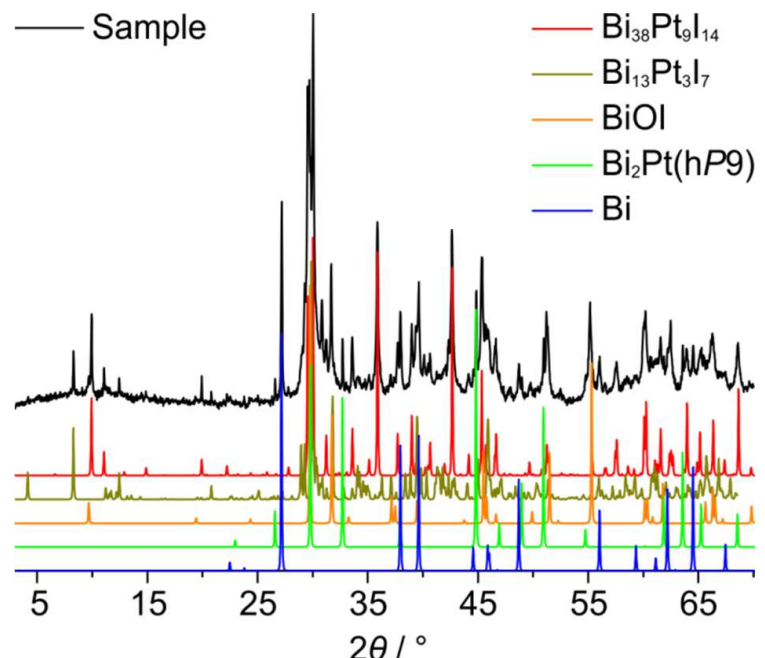

Figure S2: PXRD data of a sample after a DSC-experiment (Figure 2) with reference PXRD-pattern of $\mathrm{Bi}_{38} \mathrm{Pt}_{9} \mathrm{I}_{14}, \mathrm{Bi}_{13} \mathrm{Pt}_{3} \mathrm{I}_{7}, \mathrm{BiOI}, \mathrm{Bi}$ and $\mathrm{Bi}_{2} \mathrm{Pt}(h P 9)$. Most probably, $\mathrm{BiOI}$ was formed by reaction of $\mathrm{BiI}_{3}$ with moisture from air during the preparation of the PXRD sample. 



\begin{tabular}{cccc}
\hline & $\mathrm{Bi} / \mathrm{at} \%$ & $\mathrm{Pt} / \mathrm{at} \%$ & $\mathrm{I} / \mathrm{at} \%$ \\
\hline \multicolumn{5}{c}{ Experimental Data } \\
\hline Figure $\mathrm{S}_{3}(\mathrm{a})$ & $64.7(8)$ & $14.6(1)$ & $20.6(8)$ \\
\hline Figure $\mathrm{S}_{3}(\mathrm{~b})$ & $64(1)$ & $15(1)$ & $21(1)$ \\
\hline \multicolumn{4}{c}{ Calculated Compositions } \\
\hline $\mathrm{Bi}_{38} \mathrm{Pt}_{9} \mathrm{I}_{14}$ & 62.3 & 14.8 & 23.0 \\
\hline $\mathrm{Bi}_{36} \mathrm{Pt}_{11} \mathrm{I}_{14}$ & 59.0 & 18.0 & 23.0 \\
\hline $\mathrm{Bi}_{36} \mathrm{Pt}_{9} \mathrm{I}_{16}$ & 59.0 & 14.8 & 26.2
\end{tabular}

Figure $\mathrm{S}_{3}$ and Table S2: Scanning microscopy pictures of two different $\mathrm{Bi}_{38} \mathrm{Pt}_{9} \mathrm{I}_{14}$ crystals with marked areas/spots were EDX spectra were taken. The quantitative results are summarized in Table S2 and compared to possible theoretical compositions.

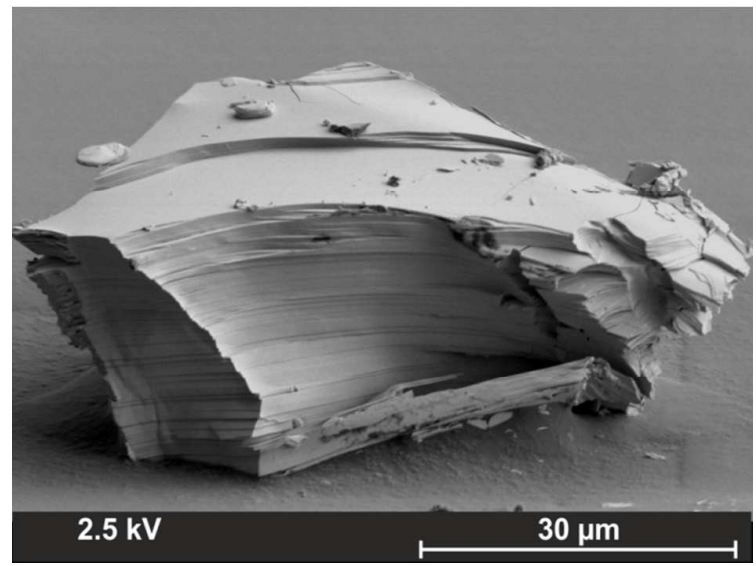

Figure $\mathrm{S}_{4}$ : Scanning electron microscopy picture of a tilted $\mathrm{Bi}_{38} \mathrm{Pt}_{9} \mathrm{I}_{14}$ crystal. 


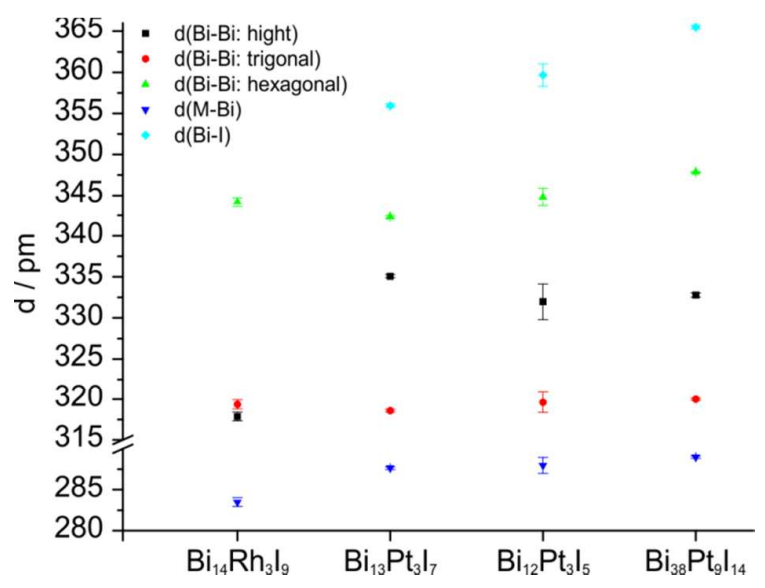

Figure $\mathrm{S}_{5}$ : Distances of bismuth atoms in the intermetallic layer to the three types of surrounding bismuth atoms (black, red, green), to the transition element (blue) and to the iodide ions of the separating iodide layer (cyan) for the all known compounds with the intermetallic layer as structural fragment. The given error bars indicate $+/-3 \sigma$ calculated from the e.s.d.s of the atomic positions.

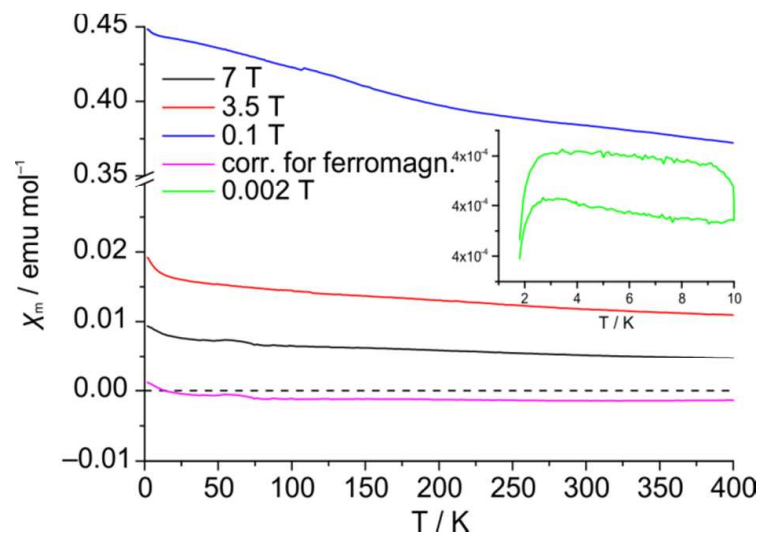

Figure S6: Magnetic susceptibility vs. temperature of $\mathrm{Bi}_{38} \mathrm{Pt}_{9} \mathrm{I}_{14}$ in different magnetic fields. The inset shows the behaviour in very low fields to check for superconductivity down to $2 \mathrm{~K}$. 


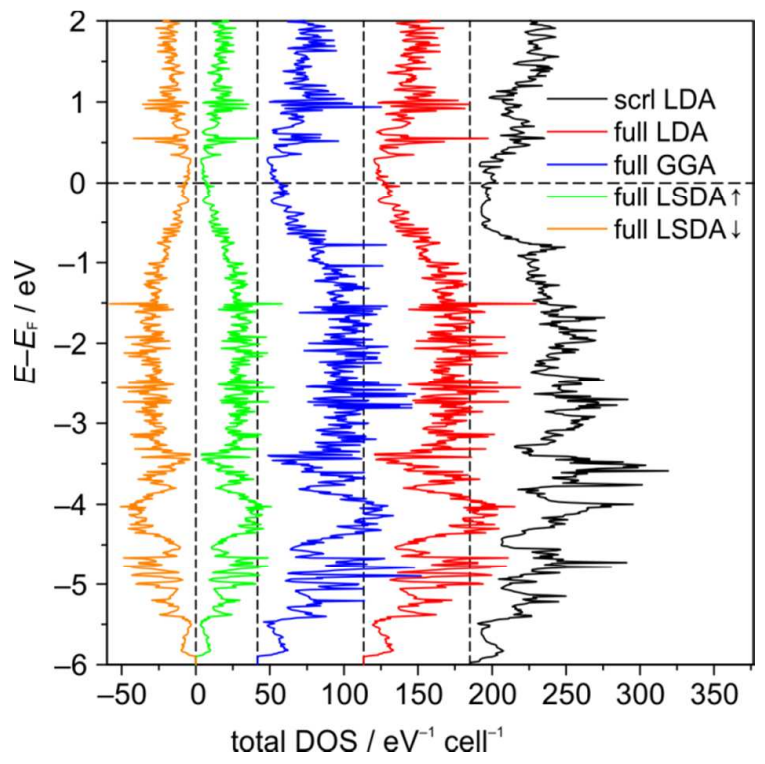

Figure S7: Total density of states (DOS) for $\mathrm{Bi}_{38} \mathrm{Pt}_{9} \mathrm{I}_{14}$ from scalar-relativistic (scrl) and full-relativistic (full) DFT calculations, with different exchange correlation potentials (local density approximation: LDA; generalised gradient approximation: GGA; local spin density approximation: LSDA). Vertical dashed lines mark the respective zero value.

Table S3: Strong and weak topological invariants, as well as the $\delta_{i}$ values calculated from the parity eigenvalues at the time-reversal invariant momenta (TRIM) for bands close to the Fermi level. The latter is indicated by the fat line.

\begin{tabular}{|c|c|c|c|c|c|c|c|c|c|c|c|}
\hline \multirow[t]{3}{*}{ band energy at $\Gamma / \mathrm{eV}$} & \multirow[t]{3}{*}{ occupation } & \multicolumn{2}{|c|}{ topological invariants } & \multicolumn{8}{|c|}{$\delta_{i}$ values at all eight TRIM } \\
\hline & & \multirow[b]{2}{*}{ strong } & \multirow[b]{2}{*}{ weak } & \multirow{2}{*}{$\begin{array}{c}\Gamma \\
\text { [ooo] }\end{array}$} & \multicolumn{2}{|c|}{$\mathrm{M}$} & \multirow{2}{*}{$\frac{\mathrm{K}}{[110]}$} & \multirow{2}{*}{$\begin{array}{c}\text { A } \\
{[001]}\end{array}$} & \multicolumn{2}{|c|}{$\mathrm{L}$} & \multirow{2}{*}{$\begin{array}{c}\mathrm{H} \\
{[111]}\end{array}$} \\
\hline & & & & & [100] & [o10] & & & {$[101]$} & [o11] & \\
\hline-0.55477 & full & 1 & (oo1) & 1 & 1 & 1 & 1 & 1 & -1 & -1 & -1 \\
\hline-0.41229 & full & 1 & (ooo) & -1 & 1 & 1 & 1 & -1 & -1 & -1 & -1 \\
\hline-0.26756 & partial & o & $(001)$ & 1 & -1 & -1 & -1 & -1 & 1 & 1 & 1 \\
\hline-0.05624 & partial & 1 & (ooo) & 1 & -1 & -1 & -1 & 1 & 1 & 1 & 1 \\
\hline 0.05404 & partial & 1 & (ooo) & -1 & 1 & 1 & 1 & 1 & 1 & 1 & 1 \\
\hline $0.0855^{2}$ & empty & 1 & (оoo) & -1 & 1 & 1 & 1 & -1 & -1 & -1 & -1 \\
\hline 0.26862 & empty & 1 & (ooo) & -1 & 1 & 1 & 1 & -1 & -1 & -1 & -1 \\
\hline
\end{tabular}

